\title{
Nonsteroidal Anti-Inflammatory Drug-Induced Colopathy in a Colorectal Cancer Screening Program
}

\author{
Sanja Borozan ${ }^{a}$ Ljiljana Vuckovic ${ }^{b}$ Brigita Smolovic $^{c}$ \\ ${ }^{a}$ Department of Endocrinology, Clinical Centre of Montenegro, Podgorica, Montenegro; ${ }^{b}$ Department of Pathology, \\ Clinical Centre of Montenegro, Podgorica, Montenegro; ' ${ }^{C}$ Department of Gastroenterohepatology, Clinical Centre of \\ Montenegro, Podgorica, Montenegro
}

\section{Significance of the Study}

- Nonsteroidal anti-inflammatory drug (NSAID)-induced colopathy should be taken into consideration as a possible differential diagnosis in patients with a positive immunochemical faecal occult blood test (iFOBT) performed in a colorectal cancer screening program. There is no need to stop NSAIDs before iFOBT.

\section{Keywords}

Nonsteroidal anti-inflammatory drugs · Colopathy ·

Diaphragms · Immunochemical faecal occult blood test .

Colorectal cancer screening

\begin{abstract}
Objective: To present a case of colopathy related to the use of diclofenac in a patient with a positive immunochemical faecal occult blood test (iFOBT) and to discuss the influence of nonsteroidal anti-inflammatory drugs (NSAIDs) on iFOBT specificity. Clinical Presentation and Intervention: A colonoscopy in a 56-year-old female presenting with a positive iFOBT revealed diaphragm-like strictures and ulcers in the right colon. While carrying out a detailed retrospective interview, she reported a chronic backache requiring long-term NSAID treatment. Conclusion: No association has been es-
\end{abstract}

\begin{tabular}{ll}
\hline KARGER & $\begin{array}{l}\text { (c) } 2018 \text { The Author(s) } \\
\text { Published by S. Karger AG, Basel }\end{array}$ \\
E-Mail karger@karger.com & $\begin{array}{l}\text { This is an Open Access article licensed under the Creative Commons } \\
\text { Attribution-NonCommercial-4.0 International License (CC BY-NC) } \\
\text { (http://www.karger.com/Services/OpenAccessicense), applicable to } \\
\text { the online version of the article only. Usage and distribution for } \\
\text { commercial purposes requires written permission. }\end{array}$
\end{tabular}

tablished between chronic use of NSAID and a false-positive iFOBT. There is no need to stop NSAIDs before performing an iFOBT in a colorectal cancer screening program.

C 2018 The Author(s)
Published by S. Karger AG, Basel

\section{Introduction}

The colorectal cancer (CRC) screening program is a public health intervention aimed at providing detection of early-stage CRC and advanced adenomas. When a positive result is found, follow-up colonoscopy is performed. However, endoscopists occasionally face unusual findings that demand a multidisciplinary approach in order to optimize the diagnostic process. NSAID-induced colopathy is a rare clinical entity, frequently unrecog- 


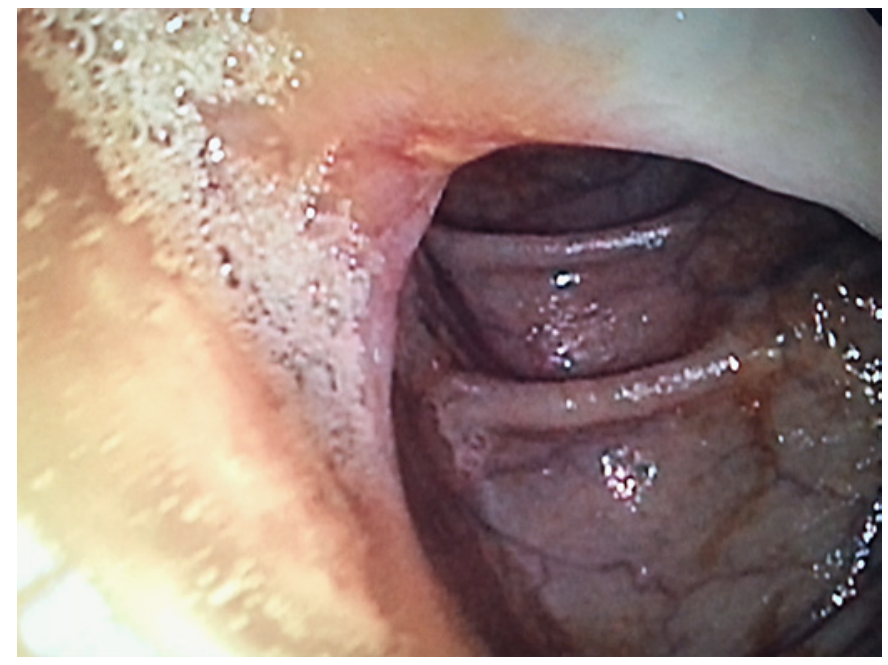

Fig. 1. A colonoscopy showing an erosion/ulceration lesion in the right colon.

nized or misinterpreted endoscopically and histologically. While lower gastrointestinal bleeding as a part of its clinical presentation is known to occur, what is not known is the frequency with which it may be a cause of a positive immunochemical faecal occult blood test (iFOBT) which, with an overall sensitivity of 0.79 and specificity of 0.94 $[1,2]$, holds considerable promise compared to guaiac methods.

\section{Case Report}

A 56-year-old asymptomatic female smoker presented with a positive iFOBT: $477.173 \mathrm{ng} / \mathrm{ml}$ (reference value $0-99 \mathrm{ng} / \mathrm{mL}$ ) performed as part of the CRC screening program for the average-risk population. Her past medical history included hypertension, diabetes, and glaucoma. The physical examination and laboratory findings were unremarkable (WBC $8.15 \times 10^{9} / \mathrm{L}$, RBC $5.04 \times$ $\left.10^{12} / \mathrm{L}, \mathrm{Hgb} 137 \mathrm{~g} / \mathrm{L}, \mathrm{MCV} 82.3 \mathrm{f} / \mathrm{L}\right)$. Colonoscopy revealed 3 lesions in the right colon: erosion/ulceration (Fig. 1) and 2 concentric diaphragm-like strictures that were passable with a scope accompanied by a mucosal lesion (Fig. 2). A further retrospective interview into the patient's medical history revealed an injury as a result of an accidental fall, causing chronic lower backache for which she had been consistently taking slow-release diclofenac tablets $200 \mathrm{mg} /$ day over the past 7 years. Histology showed mixed inflammatory cell infiltrates that included numerous lymphocytes, plasma cells, and granulocytes between the glands, but no evidence of malignancy, crypt distortion, microabscesses, or fibrosis. Based on these observations and the data, NSAID-induced colopathy was diagnosed. No lesions were subsequently detected by gastroscopy and magnetic resonance enterography.

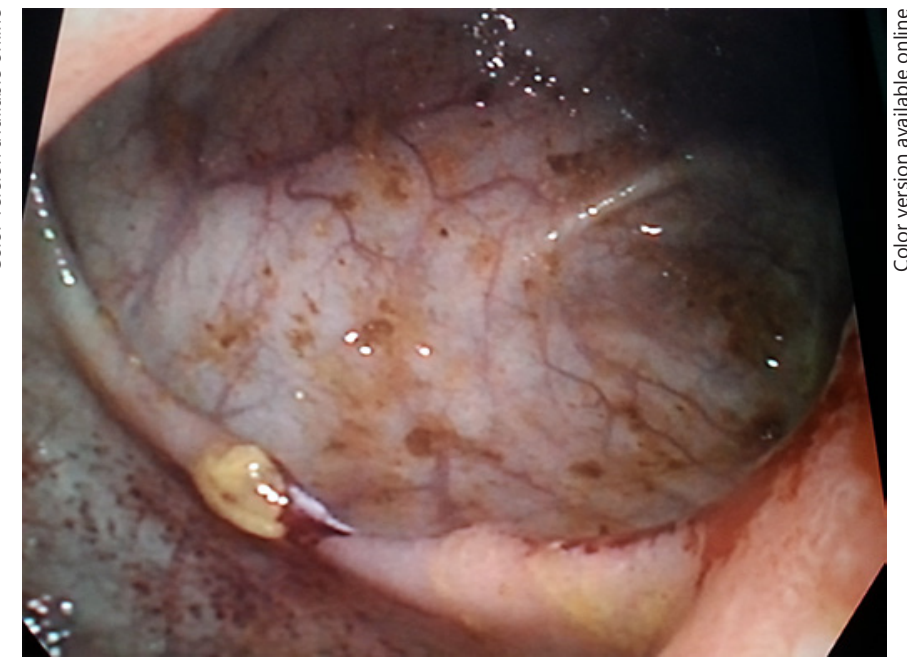

Fig. 2. A right-sided concentric diaphragm-like stricture that was passable with a scope accompanied by a mucosal lesion.

\section{Discussion}

The major disadvantage of an iFOBT in CRC screening is a false-positive result [3] caused by a variety of conditions such as inflammatory bowel disease, microscopic colitis, diverticulosis [4], and haemorrhoids. Recently, with the increasing use of slow-release and enteric-coated NSAIDs that allow more drugs to reach the colon, their influence has come to the attention of researchers. In a systematic review that analysed 45 patients diagnosed with an NSAID-induced colopathy, Munipalle et al. [5] reported diclofenac as the causative agent in most of these cases, wherein the median usage of NSAIDs was 5 years. As the gut has a narrow set of responses, the outcome is inflammation, ulceration, and the formation of fibrous diaphragm-like strictures as a result of healing [6]. NSAID-induced colopathy can be associated with usual mild lower gastrointestinal bleeding, which poses the clinical dilemma as to whether to stop NSAIDs before performing an iFOBT. If this is the case, the question remains open as to how long this should be done beforehand. In 2 clinical trials, the specificity of the iFOBT was lower in regular NSAID users $[7,8]$. This conclusion is in stark contrast to a multivariate analysis conducted on 193 veterans that found no association between regular use of NSAID and a false-positive iFOBT (OR 0.85) [9]. The same was concluded in a study by Levi et al. [10] where only the sensitivity of an iFOBT was slightly increased in NSAID users while having no impact on the specificity. 
However, the answer is still obscure; there is currently no proven need to stop NSAIDs before an iFOBT [10]. Furthermore, this case demonstrates the significance of the endoscopist's awareness of NSAID-induced colopathy as it is the cornerstone of a proper diagnosis, necessitating the additional taking of a detailed medical history. The wide availability of NSAIDs as over-the-counter drugs allows patients to use them in an uncontrolled manner, often undocumented, which is often overlooked when a medication list is recorded.

\section{Conclusion}

NSAID-induced colopathy is a rare entity that can be found in a CRC screening program. Hence, the endoscopist's awareness is crucial as it provides integrated information and allows timely diagnosis.

\section{References}

1 Ransohoff DF. What is the role of iFOBT in screening for colorectal cancer? Gut. 2007 Oct;56(10):1343-4.

2 Lee JK, Liles EG, Bent S, Levin TR, Corley DA. Accuracy of fecal immunochemical tests for colorectal cancer: systematic review and meta-analysis. Ann Intern Med. 2014 Feb;160(3): 171.

3 Garcia M, Milà N, Binefa G, Borràs JM, Espinàs JA, Moreno V. False-positive results from colorectal cancer screening in Catalonia (Spain), 2000-2010. J Med Screen. 2012 Jun; 19(2):77-82.

4 Mehrzad R, Mishra S, Faller G, Memon B, Fiore J. Right-sided diverticulosis and disparities from left-sided diverticulosis in the Vietnamese population living in Boston, Mass., USA: a retrospective cohort study. Med Princ Pract. 2015;24(4):355-61.
5 Munipalle PC, Garud T, Light D. Diaphragmatic disease of the colon: systematic review. Colorectal Dis. 2013 Sep;15(9):1063-9.

6 Adebayo D, Bjarnason I. Is non-steroidal anti-inflammaory drug (NSAID) enteropathy clinically more important than NSAID gastropathy? Postgrad Med J. 2006 Mar;82(965): $186-91$.

7 Stegeman I, de Wijkerslooth TR, Stoop EM, van Leerdam M, van Ballegooijen M, Kraaijenhagen RA, et al. Risk factors for false positive and for false negative test results in screening with fecal occult blood testing. Int J Cancer. 2013 Nov;133(10):2408-14.
8 Wong MC, Ching JY, Chan VC, Lam TY, Luk $\mathrm{AK}, \mathrm{Ng}$ SS, et al. Factors associated with falsepositive and false-negative fecal immunochemical test results for colorectal cancer screening. Gastrointest Endosc. 2015 Mar; 81(3):596-607.

9 Kahi CJ, Imperiale TF. Do aspirin and nonsteroidal anti-inflammatory drugs cause falsepositive fecal occult blood test results? A prospective study in a cohort of veterans. Am J Med. 2004 Dec;117(11):837-41.

10 Levi Z, Rozen P, Hazazi R, Vilkin A, Waked A, Maoz E, et al. Sensitivity, but not specificity, of a quantitative immunochemical fecal occult blood test for neoplasia is slightly increased by the use of low-dose aspirin, NSAIDs, and anticoagulants. Am J Gastroenterol. 2009 Apr;104(4):933-8. 